\title{
EPILOGUE - GLIMPSE OF THE FUTURE
}

\section{REDEFINING WORK TO INCREASE VALUE}

The gig economy can be viewed as the gasoline that hit the fire of change in mature economies throughout the world. Flexible work grew out of a cultural shift in how we defined and desired how we wished to work. The gig economy also grew out of a need, a need to earn more to keep pace with the inflation that nullified expected gains in purchasing power as wages increased. We no longer define work as related to the brick and mortar buildings that housed the traditional 9-to-5 job. Work from home is no longer a wish. It is a reality, and the gig economy has been the fuel that has helped companies realize new and better ways to engage labor and serve consumers.

Traditional forms of work still exist in manufacturing facilities, office buildings, and schools throughout the world, and we do not expect these critical components of an advanced society to disappear completely. We do expect artificial intelligence and robotics to change job descriptions and, in some cases, eliminate some types of current jobs. We are also experiencing, perhaps, the redefining of the need for an office-centric environment to accomplish work. The same thought applies to education as well. The need for classrooms and large events will be defined differently.

New efficiencies will embrace the use of more outsourcing. More companies will explore alternative work possibilities. The gig economy - and the opportunity to participate as a gig worker or 
under a newer label that may be the outcome of more innovation will offer more choices. High school and college graduates will spend as much time preparing for the possibility of alternative work as much as they prepare for more traditional jobs. They understand that there may be no such thing as a "traditional" job as we continue to invent the future.

Companies that attempt to utilize the popularity and attractiveness of engaging independent contractors to reduce benefits and other employment costs may find the effort, and any success gained, to be short-lived. Becoming more profitable in the short term by reducing the number of employees without a solid plan for future growth is not a growth strategy.

\section{THE GIG ECONOMY WILL SPARK MORE INNOVATION AND CREATIVITY IN HOW WE WORK}

The Federal Reserve has a broad definition of people working in the gig economy. The Fed says gig workers could be anyone from a babysitter to an Uber driver. According to that definition, Forbes reports that as many as 75 million gig workers work a gig in the United States alone. When we look at mature markets worldwide, the number is growing and on pace to reach more than one billion workers in the future. Globally, there are double-digit increases in the number of people working in the 55-65 age segment, according to a 2018 report by Morgan Stanley, The Gig Economy Goes Global. That is a clear indication that we have a mature global marketplace that is redefining work and its importance to living the lifestyle desired. Why else would an older segment in the population be looking for flexible work opportunities? There is always much discussion about the importance of appealing to millennials because they do represent the future. The older segments remain important, and the gig economy is positioned to provide much-needed opportunity and choice. Age is not a handicap to income opportunity pursuits when pursuing a gig. In fact, it makes no difference.

Global organizations such as the World Bank and International Monetary Fund are paying attention. The future of work is different, and the future is always coming faster than we think. 
What we have described as the gig economy in this book will also evolve quickly over the next few years. Pioneering gigproviding companies such as Amazon, Uber, Shopify, Etsy, and others are continuing to innovate and are expected to be disruptive again and again. When Uber disrupted the transportation industry, they did so by using advancements in technology in an innovative manner to engage thousands of drivers who would use their own cars to provide others with transportation. Uber did not want to own a fleet of vehicles; therefore, people from all walks of life benefited from a new flexible work opportunity. We also know that Uber is experimenting with driverless cars. Skeptical thoughts could easily predict that Uber will eliminate its drivers at some point; however, we see it differently. Uber does not appear to be interested in owning physical assets, so we expect a company like Uber to possibly offer leasing opportunities. Those who lease their cars will benefit from leasing without doing the driving. This creates an even greater choice of opportunity for people from all walks of life, and it will not stop there.

The emergence and popularity of Amazon Prime is also a disruptive business model. By offering customers free shipping via a subscription to Amazon Prime, the subscription segment became very profitable for Amazon (over 100 million subscribers). Customers benefit from free shipping and fantastic service. Ironically, customers who pay the Amazon Prime subscription fee may be more inclined to make purchases through Amazon consistently. As a result of this one innovative and creative approach to the business challenge of how to transfer shipping costs to the consumer, Amazon eliminated a barrier that had begun to impact consumer preferences as to which company they choose for online purchases. All companies now work to handle shipping and handling costs innovatively and creatively.

\section{GIG-PROVIDING COMPANIES WILL ADVOCATE AN ADHERENCE TO HIGH ETHICAL STANDARDS}

The gig economy does not have a national association or universal body that advocates on behalf of all gig-providing companies or all 
gig participants. We predict the gig model will begin to adapt and advocate for basic principles and values that are common to all successful business models. Some gig-providing companies are already doing this. Because the gig economy has grown so rapidly, it is clearly understood why there is no one-stop source of information or advocacy. This is where trade associations can be helpful as intermediaries when addressing challenges and the need for advocacy of the business model. However, because the gig economy is growing at such a robust growth rate, new companies are creating more platforms, and more gig workers are being attracted. Gig-providing companies should not wait to adopt and advocate good business practices, including the expectation that all gig workers engaged will always perform at a high ethical standard of expectations.

Without a commitment to high ethical standards, the gig economy could become vulnerable to bad actors no differently than any other model. In our chapter on "A Perspective on Challenges," we identified franchise models, direct selling models, and real estate models as business models that have always relied on independent contractors to do the work of representing the brand, attracting, and retaining customers.

A Universal Code of Conduct for gig workers that could be quickly agreed upon by gig providers might focus on three key points:

1. The importance of delivering an excellent customer experience.

2. Adherence to a high standard of ethics and a no-tolerance policy for unethical behavior.

3. Compliance with all local, state, and federal guidelines, regulations, and tax codes.

When the above three suggested areas are incorporated into company communication, reinforced in ongoing communication, and enforced, directly and indirectly through those who are a part of the crowd involved, all stakeholders win. The primary stakeholders are gig-providing companies, gig workers, consumers, and regulatory bodies. 


\section{OTHER INSIGHTS GAINED FROM ULTIMATE GIG PROJECT}

\section{The Work and Life Relationship Is Changing}

People are increasing their focus on the relationship between work and their quality of life. When we are involved in a traditional type of job that requires a fixed set of hours, we manage our life according to the requirements of the work. Unless we arrange to take time off, we do not schedule a time to shop, attend our children's activities, or even make medical appointments without gaining the proper approvals. However, when the worker determines the type of work and the amount of time invested, work is more likely to be integrated into the person's quality of life. In this scenario, a person can engage a gig and schedule other aspects of their life to work best for them. They can work as many hours as they desire per day and per week.

\section{Gigs Can Be Bridges}

The loss of a job may not be as detrimental as in past economies built upon traditional structures, both organizational and physical. The enormous choices in gig work opportunities can be the bridge needed between jobs. They also can provide a chance to explore skills that might be further leveraged into a microenterprise opportunity. In our traditional industrialized society, job loss could be devastating, a fact that helped spark the existence of safety nets. Job loss can occur when the demand for a product or service may diminish. This condition arises from many factors, including seasonality, reduced demand, and or diminished profits. The primary safety net has been unemployment insurance, which is not always available to those who have been eliminated, replaced, or displaced or professionals earning significant income.

Gigs and freelance opportunities can be excellent bridges. These opportunities can be activated immediately, while the job search can last for weeks or months. When we review what we have learned, a gig itself is a safety net. It can be much more powerful and meaningful because the individual controls engagement. 
Gig Workers Own Their Work, and They Perform the Work

Employees perform the work, but they do not own the work. Employees generally work for a company, and that company has much higher visibility than the individual contributor. The same could be said for many of the gig-providing companies; however, the consumer or client gets to know the gig worker who is the product or service provider. Because the gig worker owns the product or service and is the person who delivers the product or service, it has become easy for us to predict that quality and consumer value will also increase as the gig economy continues to grow as a channel of distribution. Gig workers are typically rated immediately upon delivering the product or service. The rating is an immediate evaluation of the product or service rendered, which becomes the gig worker's résumé. The difference is that this form of evaluation rates real-time performance, not historical performance. Quality and value are expected to increase for all stakeholders. This is another reason for describing gigs as an economy.

\section{Gender Inequality Has Been a Part of the Labor Discussion for an Entire Century}

It remains a debate and will continue to be a debate well in the future as traditional organizational and corporate structures remain the primary distribution methods for products and services. In the June 25, 2019, Harvard Business Review issue, Jack Zenger and Joseph Folkman wrote an article entitled Women Score Higher Than Men in Most Leadership Skills. It is a fantastic article. Organizational and corporate structures are dominated by men at the top, and women represent about $30 \%$ of all senior management positions. Zenger and Folkman stated the following:

Still, the disturbing fact is that the percentage of women in senior leadership roles in businesses has remained relatively steady since we conducted our original research. Only $4.9 \%$ of Fortune 500 CEOs and 2\% of S\&P $500 \mathrm{CEO}$ are women. And those numbers are declining globally. 
.... Women were rated as excelling in taking initiative, acting with resilience, practicing self-development, driving for results, and displaying high integrity and honesty. In fact, they were thought to be more effective in $84 \%$ of the competencies that we most frequently measure.

The gig economy model is not based on hierarchy. Therefore, women start any form of gig work as equals. The technology used to identify the talent or provider of the service is not dependent upon who but upon when. My purchases through Etsy are not about who but more about what I desire to purchase and the quality and value the vendor provides. The same is true when I use any of the many apps I enjoy. It is not about who but when if I am seeking a service. The gig economy and its use of technology will continue to level the playing field. We predict the future of gigs will be much more inclusive of women, as more women begin to realize the enormous number of choices available regarding how work can be done on their terms. Gigs empower women and can potentially shift the world of work toward greater equality.

\section{Relationships Can Create Community}

Technology is the wonderful connector between products and services, and gig workers connect the dots. However, in our interview with Kevin Guest, CEO at USANA Health Sciences, he emphasized the following particularly important fact: "You cannot build relationships into an app." This reaffirmed our observations and previous experiences with the direct selling business model. People make the difference. Independent contractors, from all walks of life, are the critical link in the supply chain that uses people to connect a product or service with a consumer. Airbnb founders, and many others who have pioneered the gig economy popularity, disrupted business models that had been in place for a century. Direct selling companies, along with real estate and insurance companies, were among the first to understand the independent contractor model's value. The older models realized that recognition is often as important as wages. Direct selling companies do this more effectively than any other 
model that fits a gig economy definition. Direct selling companies are known for their events, which gather people personally and now virtually. Gig-providing companies can learn from the direct selling models and possibly increase productivity by providing more sense of community. It could be accomplished with simple tools such as newsletters and blogs. The tools are available.

\section{The Word Freedom May Need a Broader Definition}

We do not tend to think of using the word freedom when describing work. From the traditional perspective, work has generally implied that we are giving up something (time) and providing something (expertise) that will be considered valuable to an employee. The entrepreneur has always viewed work differently.

Our dictionaries typically define freedom from a point of view relative to laws, regulations, and governance. The following type of phrase is typically included regardless of source used to find a definition of the word freedom: "absence of undue restrictions and an opportunity to exercise one's rights and powers." We now apply the word freedom to a new way of working that is inclusive of more than the word flexibility, which is a primary attribute associated with gig work according to our survey and the research conducted by others. Gig work attributes go beyond the word flexibility. Future research will explore this thought more extensively, but it is well worth noting. The growth and popularity of gigs, working when and how one desires to work, means a new type of freedom is being extended to the worker. The employee was the one making the types of decisions discussed. The worker can now make these most important decisions, meaning the worker now has the freedom to determine how and when they will work. This also translates into the amount of money one desires to earn for their efforts. This asset is beyond the asset of flexibility. We call it freedom.

\section{Microenterprise Income Opportunities Will Have a Positive Impact on the Quality of Work!}

The industrial revolution provided us with processes that improved the quality of the products and services manufactured for 
distribution to consumers. Until recently, those who manufactured or provided the products and services depended upon distribution systems that did not rely solely on the participation of individuals. As artificial intelligence and robotics take over more of the functions previously handled by humans, the quality will continue to improve. What is also changing and contributing to even more improvement is the change in how we utilize distribution channels. The gig economy is a new form of distribution.

When fixed stores or online platforms are utilized to connect with consumers, the enterprise controls the distribution channel's critical components. In the gig economy, individuals are now at the center of the distribution channel and closest to the consumer even though technology is the connector. It may appear to the customer that they are connecting directly with the company brand; however, they are not. Amazon utilizes many brand affiliates who direct potential shoppers to Amazon sites. Those affiliates have an opportunity to earn when customers they encourage to visit an Amazon site make a purchase. The affiliate is now a part of the distribution channel, even though the affiliate may be invisible to the consumer.

In most aspects of the gig economy, including direct selling, the gig worker is not invisible. They serve as an actual host, driver, taskmaster, software designer, craftsman, lessor of assets, and provider of products and services that would be unlikely to be found in the traditional marketplace. We could continue to name the thousands of roles a gig worker can play in this new gig economy. The gig worker is not only being held accountable to high performance standards (they are usually rated immediately upon delivery of service), their continued existence and sustainable success are contingent upon a process of continuous improvement. The motivation to improve is huge, and the consumer will continue to befit from greater and greater quality and value because gig workers own the work, the product, and/or the service rendered.

\section{Gigs Provide a Sense of Ownership, or at Least They Can}

Ownership changes the game. Workers who contribute to the enterprises they work are known to be more productive when the enterprise recognizes and rewards performance beyond the 
paycheck. However, when employees complete their contribution, on any given day, they are not expected to take the challenges associated with the work home to their families. Those who own the work, its quality, and the value others receive are expected to give the work the attention it deserves because that is what entrepreneurs do. Based on the research we have conducted, many gig workers do not see themselves as microentrepreneurs. When they recognize themselves as microentrepreneurs, pride in the work will increase, and a sense of ownership will prevail. Gig-providing companies will benefit from a better understanding of this key driver of performance long understood by those companies who utilize the direct selling channel of distribution.

The previous thought reminded me of my best Uber experience. The car was immaculate. The driver got out to open the door for me, offered a bottle of water, and thanked me for choosing Uber before we started the journey. I immediately complimented him and spoke of his attitude, energy, and detail associated with how he cared for his car. I could sense a slight fragrance that was just enough to let me know that care was extended to please the client. My last question to my driver was: What motivates you to provide this type of service? His response: "This is my business, and I am here to serve and please." Wow, what a refreshing ride with this entrepreneur. My continued use of Uber is more about the memory I have of such an extraordinary transportation provider. The tip I included exceeded the cost of the ride. As more gig workers understand their gig as their own businesses, the quality improves for everyone, and the brand also benefits. The gig worker, in many cases, will benefit immediately in forms that may not be immediately tangible, but the impact of the relationship and experience will be realized. This may sound philosophical; however, life seems to promise that what we hand out does come back. Of course, we are referring to the positive attributes of quality as it relates to service rendered.

\section{Gig-Providing Companies Must Support and Protect Their Human Resource}

This thought became obvious as we grew to realize the significance of gig work as being the beginning of a new economy - the gig 
economy. As we started our research, we used the words gig economy a lot. Our conversations and presentations were more focused on the attributes of work that could be embraced with flexibility and the freedom to make important decisions as to how and when the work would be done. What we learned along the way is that the gig economy is, in fact, a new form of economy. As we mentioned earlier in this book, gig workers were recognized in the language used by national governance as our country took steps to protect those whose work was suddenly disrupted by COVID-19. It was a very revealing moment as the government had now recognized the value of a channel of distribution built upon the use of independent workers who work in accordance with the hours they choose, not the hours associated with the traditional job.

Never before had this type of work been recognized from an "unemployment benefit" point of view. This moment of recognition was huge! It does not mean that such benefits should be expected in the future, but the landscape of protective or safety net products that gig workers need should rapidly increase. Gig-providing companies are not expected to provide these benefits, but they should encourage the innovation and creativity needed. They have the clout to be effective accelerators who already represent a new economy contributing over \$1 trillion to the US economy.

\section{Gigs Can Provide Serious Income!}

Our focus has always been about the incredible choices now available through gigs to earn what can be the difference between earning more than one spends during a month. Most gigs certainly satisfy this need providing income possibilities that probably fall between $\$ 500.00$ and $\$ 1,500.00$ per month. However, much more is possible. For those seeking to test themselves in a more entrepreneurial environment, a gig can be the perfect laboratory. A gig or several gigs could grow into a small enterprise. Direct selling companies are known to boast some extraordinary examples of those who have turned a part-time income opportunity into a fulltime career granted it is a small percentage of participants. When we look at the distribution of income in any society, it is always a 
few who earn the lion's share. What we observe to be different from the emergence and growth of the gig economy is that more people can test themselves. They can also opt to test themselves in a variety of ways, not one way. The job restricted the worker to specific lanes. There are no restrictions relative to gig work or the number of gigs one might try. With so many people participating as microenterprise participants, the chances of more people breaking their own glass ceilings may increase. There are neither age restrictions nor résumé requirements when engaging gig work. If more people are able to break their own glass ceilings, and we believe this will happen, the gig economy may actually have a significant impact on the way wealth is distributed but certainly a positive impact on the overall quality of life. When we can earn more than we spend, regardless of income level, we are happier.

\section{Wage Inequality}

Gig workers generally earn in accordance to a set of rules, not the résumé or amount of previous experience. Gig opportunities are also easy to explore, and potential compensation is basically the same for everyone who chooses to engage. Jobs have never offered equal pay to every participant. The gig economy, unintentionally, is providing something valuable - the potential elimination of wage inequality or at least the perception. If a microentrepreneur chooses to use a platform like Etsy to sell their creation, they will find it difficult to blame Etsy if the marketplace does not respond. If they are good at providing uniqueness to the extent the marketplace does respond, it is more a result of the quality of the product they are delivering and their own personal marketing efforts. The same can be said for any gig worker who delivers excellence in the work they do. I have experienced a gig service provider who delivered poor service. I doubt that they will succeed. I also doubt that they realized that they were the problem.

Through my many years of working with direct sellers, I always observed that some would find a way to succeed regardless of experience or inexperience. Some would not succeed, but wage inequality was never the reason. The gig economy is providing 
many more choices where wage inequality is never the issue. The outcome of the work is performance based.

\section{Positive Social Experiences}

Because of the flexibility of gig work, participants determine not only how the work will be done but also what types of social interactions they prefer within their gigs. These social interactions can provide fulfillment beyond the income earned. The traditional job environment does not offer choices relative to where the work is done and the social experience gained. In fact, the work is generally done in the same place, every day, around the same people. The social experience is not diverse. Gig work, in many cases, offers a social experience that possibly changes daily, and it is more controlled by the worker versus the traditional employer. For those looking to bring a more diverse social experience into their life and work, choosing to do gig work could be a dream come true, especially if one finds their ultimate gig.

\section{Participation in Personal Development Education Should Be Encouraged}

The independent contractor is an independent worker who can benefit from encouragement and nurturing. The nature of independence in a work relationship should not be misunderstood as meaning "leave them alone and let them do it the way they desire." Based upon what we have learned, this perception would nullify much of the tremendous potential of the gig economy to redefine the future of work. We take the position that human ingenuity is best served and nurtured when we are encouraged to grow in selfesteem, believe in our possibilities, and challenged to be the best that we can be. Traditional educational curricula and the traditional workplace have often overlooked this component of what is often referred to as "personal development." In architectural school, we learned how to design buildings, but the curricula did not include one course on designing, planning, and living life. It was my first experience with a direct selling company, as an independent 
contractor, where I first learned the importance of "me" in the work/life equation. Gig-providing companies will serve their gig workers and themselves well by encouraging participation in personal development guidance. Some may find ways to provide such guidance themselves. They only need to take a page from the direct selling playbook.

\section{Financial Education Also Is Important}

Just as gig-providing companies should encourage gig workers to participate in personal development, they would also be wise to support financial education. One of the major reasons most people seek a gig is to earn more money. Yet, financial literacy rates remain quite low. In addition, becoming an independent contractor through a gig opportunity can add a new level of financial complexity to a household. Gig workers who learn the basic skills of money management and how to navigate microentrepreneurship will be more likely to meet the financial goals that caused them to seek a gig than those who do not. Gig-providing companies should see this as an opportunity to stand out from the crowd. Companies that point their gig workers to tools and resources that support financial literacy will likely see a positive return.

\section{Business Ethics Are 10x More Important in a Gig Economy}

The ethical standards of a business have always been important, but they are rarely discussed unless the business runs afoul of laws or regulations. When this occurs, the subject of ethics rises toward the top of a priority list. However, we learned in our reading and study in preparation for the writing of this book that a company's adherence to high ethical standards should warrant audits no differently than the audits regularly done on the business components of finance, marketing, compliance with laws and regulations, customer service, supply chain, and other components considered critical to the success of the enterprise.

Human resource departments are generally responsible for the ethics of the corporate culture when the business model depends on 
employees. When the workers are gig workers, and they are projected to become the majority of the workforce, this new independent contractor labor force also needs to adhere to a high ethical standard. Adherence cannot be assumed; performance and adherence to a high ethical standard will need to be marketed, promoted, and integral to the new culture of independence, flexibility, and freedom in how the work is done. Communication of these ideals must be embraced by the new culture.

\section{There Are No Excuses}

As we travel life's journey, most of us experience challenges, especially financial challenges. The current enormous debt faced by those who had to borrow their way through college seems almost unfair. Then we discovered the statistics about household debt and savings levels, and it became easier to understand why the gig economy has grown in its appeal. People need to find ways to earn more. Traditionally, this was not easy to do. Who wants to really get excited about a part-time job that requires the same rigidity associated with the traditional full-time job? During the research for this book, I remembered several close friends who worked two traditional full-time jobs at a point in their lives. When they finished the work at one job, they immediately went to the second job.

I also remember when it was rather easy to succumb to despair when a bill could not be paid because the money had run out before the month. The gig economy provides more choices than ever when it comes to finding ways to earn additional income. Whatever our circumstance, regardless of age or résumé, the gig economy has created an opportunity. Anyone interested in earning more, paying off debt, saving and investing more, or simply doing more of what is most enjoyable should explore the possibility of a gig.

\section{Trust Is a Valuable Commodity}

The gig economy, if taken seriously by gig workers, is an economy built upon the value of trust. Trust is available to anyone who wants to embrace and leverage it as a primary tool. By extending 
the best of service, the best of professionalism, regardless of the type of work being performed, the client and customer will take notice, and the development of a trusting relationship will most likely lead to satisfied clients and consumers who may continue to embrace the brand and/or the products or services rendered. The gig economy makes it possible to leverage the value of trust.

\section{Gigs Unleash Talents, Grow Confidence, and Enhance Self-Esteem}

The gig economy makes it easier than ever before for people to explore microentrepreneurship. With a low cost of entry and a high probability of at least modest income, people from all walks of life are experiencing how it feels to be their own boss, even if it is only for a portion of their total household work. When people have more control over their finances and can see a direct correlation between their efforts and the rewards, they tend to feel more optimistic about the future and begin to dream bigger.

The exceptionally high satisfaction scores workers gave to their gig experiences in our survey showcase the positive experience people are having within the gig economy. Feeling good about your work tends to have a halo effect on other aspects of your life. We hope to explore this idea more in future research.

\section{REFLECTIONS}

We became excited about the gig economy phenomenon several years ago. It has been wonderful to observe and research and exciting to participate in work such as this. Our society is forever grateful for the inventions and utilization of technology that puts the control of so many products and services into devices that fit the palm of a hand. We are also excited about the freedoms being created by the gig economy, possibly leveling the playing field of income opportunities like none other. Of course, this would not be noteworthy if consumers were not benefiting, to a higher degree, from the quality and variety of services offered with an appealing price/value relationship. 
Of all the gig types, direct selling appears to be positioned for a new period of appeal and growth within the gig economy context. We expect even easier entry and a greater focus on customer acquisition, retention, and sponsorship of others who duplicate customer acquisition and retention behaviors to support brand-building strategies. Direct selling models are also expected to attract a much higher percentage of those who seek gigs simply because direct selling companies approach selling, customer service, rewards for sharing and involving others, recognition of performance, and providing a sense of community a bit differently.

The future has arrived! The marketplace is favorable to new ways to purchase products and services. Gig opportunities will continue to grow as a viable distribution channel and a meaningful way to earn income. The ultimate gig is ultimately the one that best matches the gig seeker's definition of what matters most.

Our ultimate motivation for taking on the work of this book, this research project, is rooted in a belief that the gig economy is helping to define a new reality; flexibility and freedom in how work is done can be achieved. We believe in the free enterprise system. We believe that by taking the time to create this book, we spark or join conversations that impact lives, which is always appealing to those of us who focus on contribution. When we focus on contribution, we best explore the possibilities that improve the quality of any product or service and the quality of all the lives we touch.

What we found in researching the gig economy convinces us that most of the workforce is going to be working differently. Therefore, it is easy for us to predict that the gig economy will continue to grow, and the choices will be even more numerous than they are today. Gig-providing companies can expect a marketplace that will continue to be favorable to part-time work opportunities. Each sector or category of gig work will become competitive for the gigproviding company as more players enter the game. The competitive spirit of free enterprise is expected to yield more benefits and better service for consumers and more income opportunities and choices for gig seekers. 


\section{REFLECTIONS FROM TWO OUTSTANDING GRADUATE STUDENTS}

We were honored to work with Christina Schreiber and Christian Panier, MBA students at the Crummer Graduate School of Business at Rollins College, Winter Park, Florida, on the Ultimate Gig. We asked them to share their conclusions as we wrapped up the project.

As we came to the close of the Ultimate Gig project, things felt bittersweet. This project morphed and twisted and grew in ways we never could have expected at the onset, and we are very grateful to have been a part of it. We moved from a more logistical, facilitating role to one that was much more hands-on. Our work on the Ultimate Gig project was not our first exposure to the literary side of business, but it was the most primary research we have done as graduate assistants so far, and we have learned a lot.

Our biggest takeaway: there is an entire hidden world of people working to make their dreams a reality and helping to reduce the monotony of day-to-day life. This world is extremely pervasive, too. Just within our own networks, we had our pick of contacts who were involved with some gig company or other - those with Etsy or Shopify stores, those who walk dogs after work, those with Twitch channels, those who drove for Uber, and the list goes on.

More than that, people were interested! Friends would ask us about the gig project, send us interesting articles from the local paper, or offer up their favorite experiences with gig companies. It is difficult to keep up with the changes in the gig economy that are being wrought by the pandemic, but we have seen people come together in new ways and have no doubt that this transformative time will inspire innovation from the farthest corners of the world. We are looking forward to seeing how companies can continue helping people connect and reach for their goals.

One of the primary reasons we applied for graduate school was to open doors and build relationships. We did not realize just how impactful that would prove. People want to help people, and people particularly want to help students. We are grateful for the friendships and relationships that have blossomed through this 
process. We are impressed with the team's dedication to getting the project done, even in the midst of global change.

We would like to say thank you to all of the executives, press teams, and other employees who took the time to chat with us about the book and about the future of the gig economy. We are inspired by the gig workers we talked to, some of whom are just starting out and others who have turned their dreams into a reality, working full-time on their gig-based businesses.

Thank you, most especially, to Dr. Greg Marshall, Lauren Lawley Head, and John Fleming for the opportunity to be a part of this project. We have always maintained that we are lucky to have a graduate assistantship that allows us room to be creative, collaborative, and inquisitive, and you have given us the room to participate in a larger conversation regarding the world we are diving into. We look forward to continuing that conversation in the future.

\section{SUMMARY /OUTLOOK}

As we arrived at this point in the work, we were both sad and glad. To conclude work such as this is also to begin a new quest to learn even more. We approached the work that went into this book intending to serve three audiences of readers:

1. The general marketplace of readers who are continually exploring possibilities because they are dissatisfied with the status quo. This is an essential segment in our society, and they read many books. They continuously drive innovation and change within their jobs, in the activities they pursue outside of their primary jobs, in their personal lives, and their families' lives. They love change and believe that life can always offer more. To this audience, we have consolidated thoughts and insights learned from experience and observation. We believe gigs should be explored by anyone capable of investing a few more hours in a day simply because we can. There is so much more that we can do with our time today than we could 25 years ago. In many ways, the gig economy is sending a message; no more excuses 
because we can now be more in control of some portions of our income possibilities. Some will find ways to make a gig their fulltime way of working. A gig can convert underutilized time into an asset.

2. We also knew we wanted to produce a body of work that could be embraced and used within the academic community. The classroom combination of professors and students is where innovation and ideas are often birthed. The brave, courageous, and brilliant students who are molded, shaped, and led by professors' wisdom and experience create new forces that enter the marketplace with every graduating class. It is truly a phenomenal process, probably why I tend to "tear up" every time I hear the song Pomp and Circumstance. A new graduating class means new brilliance is being unleashed into our society. We wanted this work to be appealing to the academic community because, if used there, it would be like having the best laboratories in the world validate and perpetuate the information and ideas within. Because of our second defined targeted audience, we invited many of our academic friends to advise, share, or participate in the work.

3. The business and regulatory communities are important. We wanted our work's outcome to be valuable to the decision-makers in companies, who are already changing the landscape of the future of work, and those who have regulatory responsibility who seek information and understanding, so crucial to the decisions they will make.

Regulatory personnel also benefit from knowledge and insights that may help to better understand the positive aspects of new phenomena that disrupt traditional practices, especially work models that can shift a tax base or redefine long-standing rules and regulations.

This book has been focused on each of the audiences we just described, and we hope that each has benefited. The future of work defines the future of the world! 